\title{
Observations regarding failure of cerebrospinal fluid shunts early after implantation
}

\author{
Sherise D. Ferguson, M.D., Nancy Michael, Ph.D., And David M. Frim, M.D., Ph.D \\ Section of Neurosurgery, The University of Chicago, Illinois
}

\begin{abstract}
$\checkmark$ Despite advances in cerebrospinal fluid (CSF) diversionary techniques, shunt failure due to infection or malfunction remains a persistent problem in hydrocephalus care. The aim of this study was to evaluate the independent predictors of early shunt survival after implantation in a large cohort of patients. The authors retrospectively reviewed the records of all patients who had undergone shunt implantation procedures at their institution during an 8-year period. They analyzed the independent predictors of shunt survival in 116 failed shunt placement procedures (infection or malfunction) by performing univariate and multivariate factorial analyses. Analysis of the 116 failed shunts in the 396 new shunt placement procedures performed revealed that age was a significant independent predictor of shunt survival time in failures due to malfunction $(\mathrm{p}<0.05)$ as well as infection $(\mathrm{p}<0.05)$. In addition, a significant relationship between patient race and shunt survival was also found. As suggested by data in other studies focused on this outcome, early shunt failure occurs sooner in younger patients. Interestingly, this study is one of few whose data have revealed that race may affect shunt failure after implantation. Specifically, shunt failure due to infection resulted in significantly shorter shunt survival time in non-white patients compared with that in white patients. Among the shunts that failed due to malfunction, however, white patients had shorter shunt survival times.
\end{abstract}

\section{KEY WORDS - hydrocephalus - cerebrospinal fluid shunt survival • cerebrospinal fluid diversion}

$\mathrm{N}$ ULSEN AND SPITZ ${ }^{13}$ described the first workable extracranial CSF shunt in 1952. Since then, shunts have revolutionized the treatment of hydrocephalus and other disturbances of CSF flow dynamics. ${ }^{7}$ Even though recent data are limited, authors of earlier studies have highlighted the affect of CSF shunting on hydrocephalus-related death. Study data collected by Chi et al. ${ }^{4}$ revealed that between 1979 and 1998, the mortality rate due to congenital hydrocephalus declined $66.3 \%$; due to spina bifida with hydrocephalus it declined by $30.4 \%$, and due to acquired hydrocephalus it declined by $67.5 \%$. In 1995, approximately 70,000 people were discharged from US hospitals every year with a diagnosis of hydrocephalus, and approximately 33,000 shunt-related procedures were performed every year, costing approximately $\$ 100$ million in national healthcare expenditures at that time. ${ }^{2}$ Unfortunately, approximately half of these dollars were spent on shunt revisions. The incidence of shunt procedures in patients with PTC has also been rising. Between 1988 and 2002, the number of shunt operations in patients with PTC increased $350 \%$ in the US. ${ }^{5}$

Despite this large volume of patients, the long-term treatment of CSF flow pathophysiologies (for example, hydro-

Abbreviations used in this paper: ANOVA = analysis of variance; $\mathrm{CSF}=$ cerebrospinal fluid; $\mathrm{PTC}=$ pseudotumor cerebri. cephalus and PTC) remains relatively poor. Even recent technological advances in shunting, such as variable pressure valves, flow control valves, antibiotic impregnated tubing, ${ }^{17}$ and endoscopic placement techniques, $, 10,15$ have failed to resolve frustration over the inability of shunts to provide reliable, uncomplicated CSF diversion.

We conducted a retrospective review of 396 shunt placement procedures to evaluate predictors of early shunt survival.

\section{CLINICAL MATERIAL AND METHODS}

We reviewed the operative and medical records of all pediatric and adult patients who had undergone shunt placement by the pediatric neurosurgery service at our institution over a 7-year period. We collected data on patient age, indication for shunting, origin of hydrocephalus, shunt type, date of shunt revision or removal, and number of subsequent revisions. In the case of failure due to shunt malfunction, we obtained information on the cause of the failure (that is, obstruction of valve, proximal catheter, or distal catheter). In the event of infection we recorded the identity of the infectious pathogen.

The primary outcome variable in this study was shunt survival time, which was defined as the time from shunt insertion to its failure as indicated by removal or revision of the shunt. The source of failure was characterized as 
either malfunction or infection. Malfunction was defined as the occurrence of symptoms in the presence of elevated intracranial pressure, as detected with lumbar puncture, shunt tap, or neuroimaging evidence of ventricular enlargement. The cause of the malfunction was further categorized as a proximal obstruction, distal obstruction, valve obstruction, valve malfunction, catheter disconnection, kinking, or migration. Infection was defined as the occurrence of symptoms in the presence of a positive CSF culture obtained through lumbar puncture or shunt tap.

It is important to emphasize that shunts inserted during the study period that did not malfunction were excluded from our analysis. Although this approach did not give a global description of how long shunts survive, we were able to determine the factors associated with shunts that had been implanted and later malfunctioned or became infected during the 7-year time frame of the study. Factors associated with shunt survival longer than 7 years were not addressed in this study, and neither were the characteristics of implanted shunts that never malfunction.

To determine the factors that predicted the duration of shunt survival time in the failed shunt group, we analyzed a series of possible predictors. These variables included indication for shunt placement, shunt type, race, age at shunt insertion, and origin of hydrocephalus. We used SPSS 10.1 for Windows (SPSS, Inc.) for our analyses. The outcome variable was continuous, that is, shunt survival in months. Our predictor variables were either dichotomous (that is, patient sex) or categorical (that is, race, shunt hardware, and origin of hydrocephalus). Dichotomous and categorical predictor variables were analyzed using a t-test and ANOVA, respectively. To analyze multiple predictors simultaneously, factorial ANOVA was used.

\section{RESULTS}

\section{Patient Demographics}

During the study period, 396 shunt placement procedures were performed . In 90 patients, 116 shunts failed after their placement over the 7-year study period. These failures formed the material for our study. Implanted shunts that did not fail were excluded from our analysis, meaning that long-surviving shunts ( $\geq 7$ years) were not evaluated.

Demographically, the study group was predominantly male $(59.5 \%)$ and non-white $(54.3 \%)$, with a mean age of $119.7 \pm 202.4$ months at the time of shunt placement (Table 1). The majority of shunts had been placed for the

TABLE 1

Summary of characteristics in 90 patients with 116 shunt failures*

\begin{tabular}{|c|c|c|c|}
\hline \multirow[b]{2}{*}{ Characteristic } & \multicolumn{3}{|c|}{ No. of Cases (\%) } \\
\hline & All Shunt Failures & Failure Due to Infection & Failure Due to Malfunction \\
\hline \multicolumn{4}{|l|}{$\operatorname{sex}$} \\
\hline male & $69(59.5)$ & $21(63.6)$ & $48(57.8)$ \\
\hline female & $47(40.5)$ & $12(36.4)$ & $35(42.2)$ \\
\hline \multicolumn{4}{|l|}{ race } \\
\hline white & $38(32.8)$ & $3(9.1)$ & $35(42.2)$ \\
\hline black & $51(44.0)$ & $18(54.5)$ & $33(39.8)$ \\
\hline other & $15(12.9)$ & $8(24.2)$ & $7(8.4)$ \\
\hline unknown & $12(10.3)$ & $4(12.1)$ & $8(9.6)$ \\
\hline \multicolumn{4}{|l|}{ indication for shunt } \\
\hline hydrocephalus & $102(87.9)$ & $31(93.9)$ & $71(85.5)$ \\
\hline PTC & $14(12.1)$ & $2(6.1)$ & $12(14.4)$ \\
\hline \multicolumn{4}{|l|}{ shunt type } \\
\hline VP & $92(79.3)$ & $28(84.8)$ & $64(77.1)$ \\
\hline LP & $14(12.1)$ & $2(6.1)$ & $12(14.4)$ \\
\hline VA & $3(2.6)$ & $1(3)$ & $2(2.4)$ \\
\hline V-gallbladder & $1(0.9)$ & $1(3)$ & $0(0.0)$ \\
\hline V-pleural & $4(3.4)$ & $1(3)$ & $3(3.6)$ \\
\hline other & $2(1.7)$ & $0(0)$ & $2(2.4)$ \\
\hline (cyst peritoneal, cisterna magna pleural) & & & \\
\hline \multicolumn{4}{|l|}{ origin of hydrocephalus } \\
\hline posthemorrhagic & $38(37.2)$ & $12(36.4)$ & $26(31.3)$ \\
\hline postmeningitic & $9(8.8)$ & $3(9.7)$ & $6(8.4)$ \\
\hline $\begin{array}{l}\text { congenital } \\
\text { (aqueductal stenosis, encephalocele, } \\
\& \text { holoprosencephaly) }\end{array}$ & $14(13.7)$ & $5(15.1)$ & $9(10.8)$ \\
\hline $\begin{array}{l}\text { obstruction (arachnoid cyst, tumor, } \\
\text { pineal cyst, \& Dandy-Walker cyst) }\end{array}$ & $9(8.8)$ & $4(12.9)$ & $5(7.0)$ \\
\hline MM & $5(4.9)$ & $1(3.2)$ & $4(5.6)$ \\
\hline posttraumatic & $4(3.9)$ & $2(6.5)$ & $2(2.8)$ \\
\hline $\mathrm{NPH}$ & $2(2.0)$ & $0(0)$ & $2(2.8)$ \\
\hline other & $19(16.3)$ & $3(9.0)$ & $16(19.3)$ \\
\hline unknown & $16(15.7)$ & $3(9.7)$ & $13(18.3)$ \\
\hline mean patient age at insertion (mos) & 119.7 & 54.2 & 146.0 \\
\hline mean duration of shunt survival (mos) & 6.3 & 4.3 & 7.1 \\
\hline
\end{tabular}

* LP = lumboperitoneal; $\mathrm{MM}=$ myelomeningocele; $\mathrm{NPH}=$ normal-pressure hydrocephalus; $\mathrm{VA}$ = ventriculoatrial; V-gallbladder = ventriculogallbladder; $\mathrm{VP}=$ ventriculoperitoneal; V-pleural = ventriculopleural. 
treatment of hydrocephalus $(87.9 \%)$ and the remaining ones for the treatment of PTC $(12.1 \%)$. The mean overall survival time of newly placed shunts was $6.3 \pm 11.8$ months. Among these newly placed shunts, $28.5 \%$ of failures (33 shunt failures) were attributable to infection, whereas $71.5 \%$ (83 shunt failures) were due to malfunction. In the infection group, Staphylococcus epidermis was the most common pathogen (54\%), followed by $S$. aureus (25\%), methicillin-resistant S. aureus (12\%), Pseudomonas aeruginosa (3\%), and other bacteria (6\%) including Serratia and Corynebacterium. In the malfunction group, the most frequent cause for revision was proximal obstruction $(38 \%)$. The origins of hydrocephalus were similar in the infection and malfunction groups. In both groups, postintraventricular hemorrhage hydrocephalus due to prematurity was the dominant cause $(36.4 \%$ of the infection group and $31.3 \%$ of the malfunction group) followed by hydrocephalus due to congenital causes $(15.1 \%$ of the infection group and $10.8 \%$ of the malfunction group). The mean duration of shunt survival in the infection and malfunction groups were $4.3 \pm 10.7$ months and $7.1 \pm 12.2$ months, respectively.

\section{Univariate Analysis}

Overall Sample. In the overall sample, there was no significant relationship between shunt survival and any of the following variables: patient sex, race, shunt type, and origin of hydrocephalus. In analyzing the entire sample, trends toward significance emerged for the variables of indication for shunt insertion and age at insertion. Shunts placed for hydrocephalus tended to have a longer survival than those placed for PTC. Hydrocephalus shunts lasted a mean of $6.7 \pm 12.5$ months, whereas those placed for PTC lasted a mean of $3.6 \pm 3.3$ months $(\mathrm{t}(74.3)=1.9, \mathrm{p}=0.051)$. Regarding the patient age at insertion, shunts placed between 0 and 6 months of age had a mean survival time of $4.2 \pm 6.0$ months compared with shunts placed after 6 months of age, which lasted a mean of $7.8 \pm 14.3$ months. This association also showed a trend toward significance $(\mathrm{t}(98.4)=1.86, \mathrm{p}=0.067)$. We found a significant relationship between the cause of shunt failure (infection or malfunction) and shunt survival. Shunts that failed due to malfunction were approximately twice as likely to last longer than 6 months $(32.5 \%)$ compared with those that failed due to infection $\left(15.2 \% ; \chi^{2}=3.57, \mathrm{p}<0.05\right)$.

Shunt Infection Group. In the infection group, a t-test revealed a relationship between shunt survival and patient sex; that is, the mean shunt survival time in male patients was $1.7 \pm 2.0$ months compared with $8.9 \pm 16.8$ months in female patients. This association trended toward significance $(\mathrm{t}(31)=1.96, \mathrm{p}=0.06$; Table 2). Furthermore, among the shunts that became infected in less than 6 months, $71.4 \%$ resided in male patients. In contrast, only $20 \%$ of shunts that survived longer than 6 months resided in male patients. We also found a significant relationship between patient race and shunt survival. In the infection group, the mean shunt survival period in white patients (20.4 months) was almost 7 times that in non-white patients (3.1 months). This difference was found to be significant with ANOVA $(\mathrm{F}(2,30)=4.6, \mathrm{p}<0.05)$.

The effect of the origin of hydrocephalus on shunt survival according to univariate ANOVA showed a statisti- cally significant relationship in the infection group $(\mathrm{F}(4$, $26)=6.6, p<0.01)$. Results of a post-hoc analysis revealed that postmeningitic hydrocephalic patients (three patients) had a significantly longer shunt survival time (28 months) than did those who had hydrocephalus attributable to all other causes in the cohort (Table 2), although the size of this group was very small. Last, we found a significant relationship between the patient age at insertion and shunt survival time in this infection subgroup. Patients who had undergone shunt insertion at ages greater than 17 years had significantly longer shunt survival (21 \pm 31.3 months) than their younger counterparts $(\mathrm{F}(2,30)=5.1, \mathrm{p}<0.05)$.

Shunt Malfunction Group. In the malfunction group, nonwhite patients had shunt survival of 10.5 months compared with 3.8 months in white patients. This result trended toward significance $(F(2,80)=2.95, p=0.058)$. Additionally, in this subgroup, patients who received shunts between the ages of 2 and 17 years had the longest shunt survival $(14.9 \pm 21.3$ months $)$, and this result was found to be significant on ANOVA $(\mathrm{F}(2,79)=4.4, \mathrm{p}<0.05)$. We found no significant relationship between patient sex and shunt survival time in this group.

\section{Factorial Analysis of Variance}

We conducted a factorial ANOVA and entered age, origin of hydrocephalus, sex, and race as predictors of shunt survival. None of these factors were independent predictors of shunt survival.

TABLE 2

Univariate analysis of factors affecting shunt survival*

\begin{tabular}{|c|c|c|c|c|}
\hline Variable & No. & Mean (mos) & F Statistic & $\mathrm{p}$ Value \\
\hline \multicolumn{5}{|l|}{ infection group } \\
\hline $\operatorname{sex}$ & & & $\mathrm{NA} \dagger$ & 0.06 \\
\hline male & 21 & $1.7 \pm 2.0$ & & \\
\hline female & 12 & $8.9 \pm 16.8$ & & \\
\hline race & & & 4.6 & $<0.05$ \\
\hline white & 13 & $20.4 \pm 32.0$ & & \\
\hline non-white & 26 & $3.1 \pm 5.5$ & & \\
\hline unknown & 4 & $0.5 \pm 0.2$ & & \\
\hline origin of hydrocephalus & & & 6.58 & $<0.01$ \\
\hline posthemorrhagic & 12 & $2.3 \pm 3.9$ & & \\
\hline postmeningitic & 3 & $28.0 \pm 28.3$ & & \\
\hline congenital & 5 & $1.7 \pm 2.6$ & & \\
\hline other & 10 & $2.0 \pm 2.2$ & & \\
\hline unknown & 3 & $0.6 \pm 0.5$ & & \\
\hline patient age (yrs) & & & 5.11 & $<0.05$ \\
\hline $0-2$ & 23 & $2.8 \pm 5.9$ & & \\
\hline $2.1-17$ & 7 & $2.3 \pm 2.1$ & & \\
\hline$>17$ & 3 & $21.2 \pm 31.3$ & & \\
\hline \multicolumn{5}{|l|}{ malfunction group } \\
\hline race & & & 2.9 & 0.058 \\
\hline white & 38 & $3.8 \pm 4.7$ & & \\
\hline non-white & 37 & $10.5 \pm 16.3$ & & \\
\hline unknown & 8 & $7.6 \pm 11.4$ & & \\
\hline patient age (yrs) & & & 4.42 & $<0.05$ \\
\hline $0-2$ & 45 & $5.8 \pm 9.2$ & & \\
\hline $2.1-17$ & 16 & $14.9 \pm 21.3$ & & \\
\hline$>17$ & 21 & $4.2 \pm 4.0$ & & \\
\hline
\end{tabular}

$*$ NA = not applicable

$\dagger \mathrm{t}=1.95$. 


\section{DISCUSSION}

Despite the evident benefits of CSF diversion, shunting remains plagued with a high complication rate. This retrospective study of 396 adult and pediatric cases involving the placement of shunts for either hydrocephalus or PTC was undertaken to understand the predictors of a high rate of complications in the first few years after implantation; 116 shunts failed within the 7-year study period. We evaluated the following possible predictors: indication for CSF diversion, origin of hydrocephalus, patient age at shunt insertion, patient race, and shunt type.

Among the shunts that had failed due to infection, we found that patients with postmeningitic hydrocephalus had a longer average shunt life than did those with other disease origins. All other hydrocephalus causes were associated with a mean shunt survival time of less than 3 months. Note that a small number of patients made up the postmeningitic hydrocephalus group, making our result very limited. There is a general discrepancy within the literature regarding the effect of hydrocephalus origins on shunt survival. In an earlier study, Piatt and Carlson ${ }^{14}$ analyzed 727 shunt operations to determine predictors of shunt survival, and they found no relationship between hydrocephalus origins and the incidence of shunt complications. In a more recent study, McGirt and colleagues ${ }^{12}$ evaluated shunt survival in 353 pediatric patients, and their results agreed with those of Piatt and Carlson. ${ }^{14}$ In contrast, several authors suggest that hydrocephalic origin does in fact affect shunt survival. In a 1995 study involving 105 pediatric patients, the authors demonstrated that patients with intraventricular hemorrhage have shorter shunt survival times than those without hemorrhage. ${ }^{3}$ Furthermore, Quigley et al., ${ }^{16}$ who examined 41 cases of CSF shunt infection, suggested that only intraventricular hemorrhage as an origin correlated with sepsis risk. An increased complication risk has also been associated with myelomeningocele. In a study of the CSF shunt infection risk, Enger and coauthors ${ }^{8}$ determined that patients with myelomeningocele had a higher infection risk compared with patients with hydrocephalus due to other causes. Additionally, data from an earlier study of 431 patients with newly inserted CSF shunts revealed that patients with myelomeningocele were significantly more prone to infection than those with congenital hydrocephalus, thus highlighting the potential effect of origins on shunt survival. ${ }^{1}$ Conversely, results of another study suggest that patients with neural tube defects have longer shunt survival times than patients with other disease origins. ${ }^{11}$ Notably, the majority of the studies mentioned above included both shunt placements and revisions in their analyses, whereas we addressed newly placed shunts that had failed within the study time frame.

We found univariate relationships between patient race or age and shunt survival in the infection subgroup. Age was a predictor of shunt survival time among devices that had failed due to infection; patients older than 17 years had a longer shunt survival period than those who were younger. There was also an effect of age on shunt survival time for devices that had failed because of malfunction, with patients 2 to 17 years having longer shunt survival times than those who were either younger or older. Our finding that patient age is a predictor of shunt survival is in keeping with data from numerous shunt survival studies. ${ }^{11,12,14,18}$ It has been suggested that this observation is related to both immunological deficiency and particular bacterial flora in infants. ${ }^{6}$ To our knowledge, however, our data are the first to show a shunt survival relationship with patient race. In the shunt infection group, patients who were white had significantly longer shunt survival times than non-whites. We suspect that multiple intertwining factors contributed to this result. First, regarding the failure due to infection group, non-white patients may have experienced shorter survival times because of the increased incidence of prematurity among this group and thus the predisposition to a general immunocompromised state. Moreover, one cannot exclude the potential impact of socioeconomic factors on this group.

The factors that were significant on univariate analysis (race, age, origin of hydrocephalus) did not remain significant on factorial ANOVA. This result should not be interpreted as meaning that none of the factors matter; rather it suggests that the factors may overlap in their influence on shunt survival time. Future evaluation with larger samples would allow better detection of the predictive ability.

\section{CONCLUSIONS}

In summary, our study data add to the body of literature reporting on shunt survival in the first few years after implantation. Consistent with results of previous studies, we found that younger patients had a shorter shunt survival time. Additionally, our findings indicated that race may play a role in CSF shunt survival. The finding of a race-related factor in shunt survival deserves further study.

\section{Acknowledgment}

Nancy Michael is deceased.

\section{References}

1. Ammirati M, Raimondi AJ: Cerebrospinal fluid shunt infections in children. A study on the relationship between the etiology of hydrocephalus, age at the time of shunt placement, and infection rate. Childs Nerv Syst 3:106-109, 1987

2. Bondurant CP, Jimenez DF: Epidemiology of cerebrospinal fluid shunting. Pediatr Neurosurg 23:254-259, 1995

3. Brownlee RD, Dold ON, Myles ST: Intraventricular hemorrhage complicating ventricular catheter revision: incidence and effect on shunt survival. Pediatr Neurosurg 22:315-320, 1995

4. Chi JH, Fullerton HJ, Gupta N: Time trends and demographics of deaths from congenital hydrocephalus in children in the United States: National Center for Health Statistics data, 1979 to 1998. J Neurosurg 103 (2 Suppl):113-118, 2005

5. Curry WT Jr, Butler WE, Barker FG II: Rapidly rising incidence of cerebrospinal fluid shunting procedures for idiopathic intracranial hypertension in the United States, 1988-2002. Neurosurgery 57:97-108, 2005

6. Dallacasa P, Dappozzo A, Galassi E, Sandri F, Cocchi G, Masi M: Cerebrospinal fluid shunt infections in infants. Childs Nerv Syst 11:643-649, 1995

7. Drake JM, Kestle JR, Tuli S: CSF shunts 50 years on-past, present and future. Childs Nerv Syst 16:800-804, 2000

8. Enger PO, Svendsen F, Wester K: CSF shunt infections in children: experiences from a population-based study. Acta Neurochir (Wien) 145:243-248, 2003

9. Kellnar S, Boehm R, Ring E: Ventriculoscopy-aided implanta- 
tion of ventricular shunts in patients with hydrocephalus. J Pediatr Surg 30:1450-1451, 1995

10. Lewis AI, Keiper GL Jr, Crone KR: Endoscopic treatment of loculated hydrocephalus. J Neurosurg 82:780-785, 1995

11. Liptak GS, McDonald JV: Ventriculoperitoneal shunts in children: factors affecting shunt survival. Pediatr Neurosci 12: 289-293, 1985-1986

12. McGirt MJ, Leveque JC, Wellons JC III, Villavicencio AT, Hopkins JS, Fuchs HE, et al: Cerebrospinal fluid shunt survival and etiology of failures: a seven-year institutional experience. Pediatr Neurosurg 36:248-255, 2002

13. Nulsen FE, Spitz EB: Treatment of hydrocephalus by direct shunt from ventricle to jugular vein. Surg Forum 2:399-403, 1952

14. Piatt JH Jr, Carlson CV: A search for determinants of cerebrospinal fluid shunt survival: retrospective analysis of a 14-year institutional experience. Pediatr Neurosurg 19:233-241, 1993

15. Punt DW, Jaspan T, Worthington B: Neuroendoscopy in the management of hydrocephalus. Eur J Pediatr Surg 5:39-45, 1995
16. Quigley MR, Reigel DH, Kortyna R: Cerebrospinal fluid shunt infections. Report of 41 cases and a critical review of the literature. Pediatr Neurosci 15:111-120, 1989

17. Sciubba DM, Stuart RM, McGirt MJ, Woodworth GF, Samdani A, Carson B, et al: Effect of antibiotic-impregnated shunt catheters in decreasing the incidence of shunt infection in the treatment of hydrocephalus. J Neurosurg 103 (2 Suppl): 131-136, 2005

18. Tuli S, Drake J, Lawless J, Wigg M, Lamberti-Pasculli M: Risk factors for repeated cerebrospinal shunt failures in pediatric patients with hydrocephalus. J Neurosurg 92:31-38, 2000

Manuscript received January 4, 2007.

Accepted in final form March 13, 2007.

Address reprint requests to: David M. Frim, M.D., Ph.D., Pediatric Neurosurgery, MC4066, The University of Chicago Children's Hospital, 5841 South Maryland Avenue, Chicago, Illinois 60637. email: dfrim@surgery.bsd.uchicago.edu. 